\title{
JUURNAL_RU
}

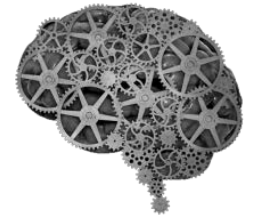

COMPANY GROUP "INTELLEKT"

Веретенникова В.Б. Автономное образовательное учреждение дополнительного образования Удмуртской Республики «Институт развития образования» Ижевск, Россия

doi: 10.18411/lj2016-9-1-03

idsp 000001: lj2016-18-1-03

\section{Элементы дистанционного курса как средство обучения родителей в современной системе дошкольного образования}

\section{Аннотация.}

Представлен опыт организационно-методического сопровождения курса «Управление качеством дошкольного образования» с элементами интерактивных технологий, направленный наформирование и развитие базовых компетенций родителей в условиях реализации федерального государственного образовательного стандарта дошкольного образования.

Ключевые слова: дистанционный курс, таксономическая модель, базовые компетенции, структура знаний, структура умений, уровень мотивации

Согласно Закону «Об образовании в Российской Федерации», который признает приоритет семейного воспитания, «родители имеют преимущественное право на обучение и воспитание детей перед всеми другими лицами». В связи с этим, одним из требований Федерального государственного образовательного стандарта (ФГОС), как и профессионального стандарта, является необходимость взаимодействия дошкольной организации с семьями воспитанников, а также обеспечение психолого-педагогической поддержки и повышения компетентности родителей в вопросах развития и образования детей. При этом возникает проблема разработки организационно-методического сопровождения родителей к осознанному выполнению своих функций по образованию детей.

Для решения этой проблемы в одной из дошкольных организаций г. Ижевска разработан авторский курс «Управление качеством дошкольного 
образования»[3], предусматривающий формирование и развитие базовых компетенций родителейи основанный на технологии развивающего обучения. Предусмотрены различные интерактивные техники, направленные на активную совместную деятельность субъектов образовательного процесса: кейс-метод, проблемные консультации, деловые игры и дискуссии.

Принятая в рамках курса структурабазовых компетенций субъектов образовательного процесса (педагога, ребенка и его родителей) [1]представлена на рис. 1.

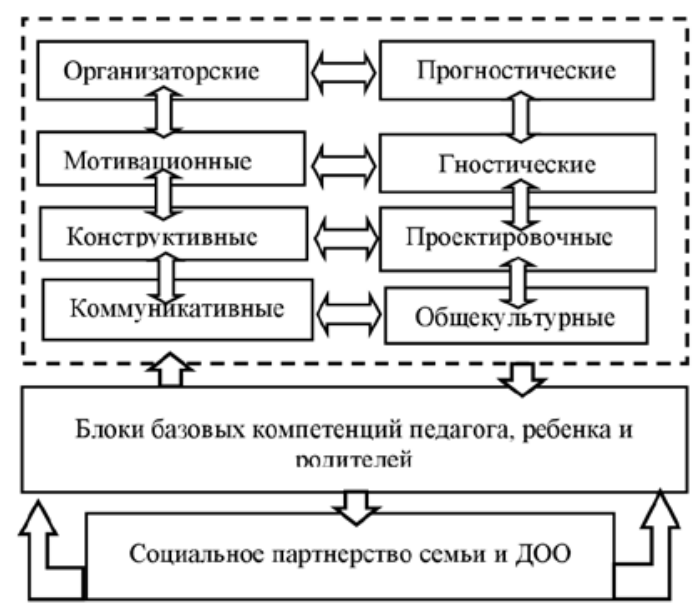

Рис.1. Структура базовых компетенций субъектов образовательного процесса в системе дошкольного образования

В данной структуре инструментом сотрудничества в образовательных отношениях социальных институтов общества: семьи и дошкольной организации - выступает социальное партнерство [2].

Тематика курса, представленная на рисунке. 2, соответствует этапам организации социального партнерства.

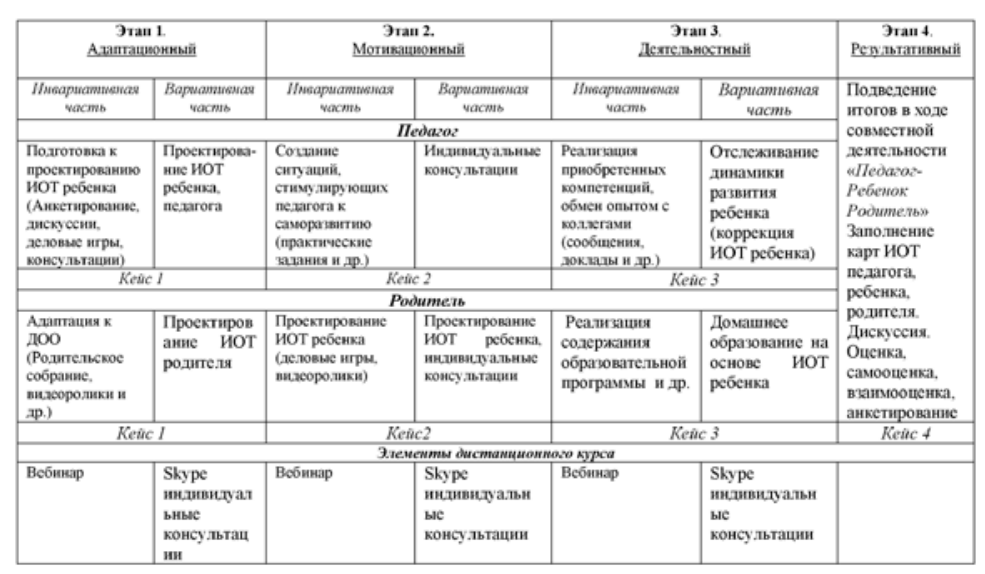

Рис.2.Фрагмент организации социального партнерства семьи и ДОО по курсу «Управление качеством дошкольного образования» 
Каждый этап включает:

- инвариантную часть, предусматривающую расширение нормативноправовых, общепедагогических, психологических знаний как компонентов базовых компетенций педагога и родителей;

- вариативную часть, предполагающую индивидуальную деятельность педагога и родителей, ориентированную на практическое применение теоретических положений курса на основе интерактивных методов обучения.

Наш опыт показывает, что интерактивные техники в социальном партнерстве способствуют развитию базовых компетенций педагогов и родителей, в частности:умению формулировать и задавать вопросы, отстаивать свою точку зрения, выявлять проблемы и решать их; анализировать, синтезировать и оценивать информацию. При этом учитывается специфика процесса формирования и развития базовых компетенций: кратковременность и интенсивность; учет возрастных, психологических особенностей субъектов образовательного процесса, уровня их теоретической и профессиональной подготовки.

Наиболее сложные для родителей дискуссионные темы занятий представлены в виде элементовдистанционного курса, при котором родители полностью отделены друг от друга в пространстве, но имеют возможность в любой момент поддержать диалог с помощью средств телекоммуникации. В таблице 1 представлена тематика проводимых в таком формате занятий.

Тематика дистаничионного курса для родителей детей раннего возраста

Таблица 1

\begin{tabular}{|c|l|}
\hline$№$ & \multicolumn{1}{|c|}{ Название тем вебинаров } \\
\hline 1. & Индивидуальные особенности поведения детей в период адаптации \\
\hline 2. & Родительские базовые компетенций в системе дошкольного образования \\
\hline 3. & Индивидуальная образовательная траектория ребенка в системе ДО \\
\hline 4. & Домашнее образование ребенка раннего возраста \\
\hline 5. & Реализация направлений развития с помощью художественного творчества ребенка раннего возраста \\
\hline
\end{tabular}

Элементы дистанционного курсане только позволяют преодолевать физические препятствия для коммуникации, но такжеускоряют и облегчают все этапы социального партнерства, включая формирование и развитиебазовых компетенцийродителей, что придают целостность системе дошкольного образования.

Базовые компетенции родителейрассматриваются нами как совокупность знаний, умений, навыков и способностей, обеспечивающих успешную 
реализацию индивидуальной образовательной траекторииребенка в домашнем образовании.

Положительным моментом для родителейявляется гибкость дистанционного курса, чтодает возможность общаться в удобное для них Ведущийкурса помогает родителю не только организовать домашнее образование ребенка, но и предоставляет ссылки на дополнительные источники информации, обеспечивает иллюстративным и демонстрационным материалом, организует работу в соответствии соспецификой дошкольной педагогики. Обратная связь с родителями осуществляется при помощи интерактивных опросов, а также индивидуальных консультаций с использованием электронной почты и Skype.

Каждый сценарийдистанционного обучения закладывается по таксономии образовательных целей родителей, установленных в контексте требований Федерального государственного образовательного стандарта. Используемая нами таксономическая модель[7,8,9] представлена на рисунке 3.

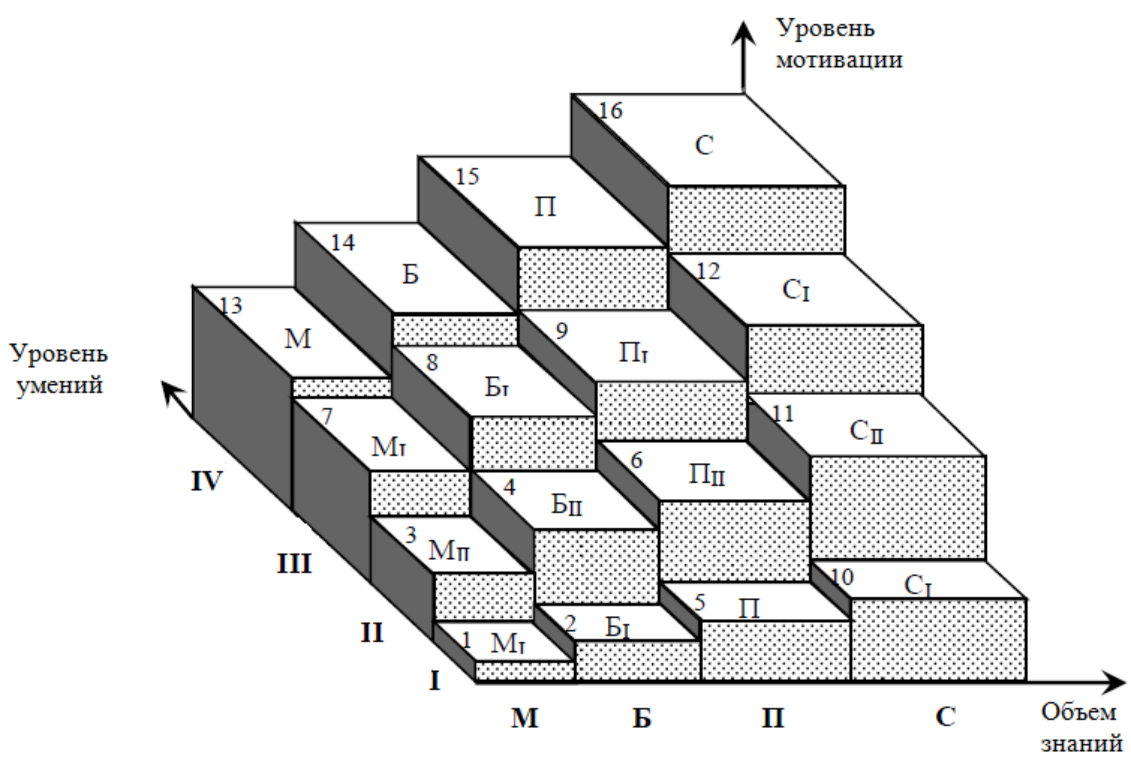

Рис. 3. Таксономическая модель формирования базовых компетенций педагогов и родителей дошкольников

Ее содержание в сжатом виде представлено в таблице 2 (где БКР - базовые компетенции родителей в образовательном процессе). 
Таблииа 2.

Содержание таксономической модели формирования базовых компетенций родителей дошкольников

\begin{tabular}{|c|c|c|c|c|}
\hline $\begin{array}{l}\text { Таксономическая } \\
\text { модель уровней } \\
\text { формирования БКР }\end{array}$ & Уровень БКР & $\begin{array}{l}\text { Номер } \\
\text { ячейки } \\
\text { модели }\end{array}$ & $\begin{array}{l}\text { Код } \\
\text { БКР }\end{array}$ & Цель \\
\hline \multirow[t]{4}{*}{ Свойство Качество } & \multirow[t]{4}{*}{ Нормативный } & 1 & Пк-2 & \multirow{4}{*}{$\begin{array}{l}\text { Формирование и развитие базовых } \\
\text { компетенций в реализации } \\
\text { программы дошкольной } \\
\text { организации в домашнем } \\
\text { образовании }\end{array}$} \\
\hline & & 2 & Пк-1 & \\
\hline & & 3 & Пг-1 & \\
\hline & & 4 & Об-7 & \\
\hline \multirow{5}{*}{$\begin{array}{l}\text { Системные } \\
\text { компетенции }\end{array}$} & \multirow[t]{5}{*}{ Системный } & 5 & Об-5 & \multirow{5}{*}{$\begin{array}{l}\text { Формирование и развитие системы } \\
\text { базовых компетенций по } \\
\text { реализации ИОТ (ребенка, } \\
\text { родителя) в домашнем образовании }\end{array}$} \\
\hline & & 6 & $\Gamma \mathrm{H}-3$ & \\
\hline & & 7 & $\Gamma \mathrm{H}-7$ & \\
\hline & & 8 & MT-3 & \\
\hline & & 9 & Op-3 & \\
\hline \multirow[t]{4}{*}{ Компетентность } & \multirow[t]{4}{*}{ Креативньій } & 10 & Об-6 & \multirow{4}{*}{$\begin{array}{l}\text { Совершенствование системных } \\
\text { базовых компетенций в } \\
\text { образовательной деятельности в } \\
\text { домашнем образовании }\end{array}$} \\
\hline & & & $\Gamma \mathrm{H}-5$ & \\
\hline & & 11 & Мт-6 & \\
\hline & & 12 & Op-5 & \\
\hline \multirow[t]{2}{*}{ Мастерство } & \multirow{2}{*}{$\begin{array}{l}\text { Профессионально } \\
\text { креативньий }\end{array}$} & 13 & MT-1 & \multirow[b]{2}{*}{$\begin{array}{l}\text { Развитие базовых компетенций в } \\
\text { проектировании образовательной } \\
\text { деятельности субъектов } \\
\text { образовательного процесса в } \\
\text { дошкольной организации и } \\
\text { домашнем образовании }\end{array}$} \\
\hline & & 14 & Км-4 & \\
\hline
\end{tabular}

Обозначения, принятые в кодах представленных базовых компетенций: Пк-проектировочные; Об-общекультурные; Пг-прогностические; Гнгностические; Ор-организационные; Мт-мотивационные; Кн-конструктивные; Км-коммуникативные.

\section{Цели каждого уровня конкретизируются в виде компетентностно-} ориентированного тезауруса, который рассматривается нами как иерархическая совокупность взаимосвязанных базовых компетенций субъектов образовательного процесса в системе дошкольного образования.

\section{Фрагмент компетентностно-ориентированного тезауруса родителя} представлен в таблице 3.

Таблииа 3.

Компетентностно-ориентированный тезаурус родителя в индивидуальной образовательной траектории (Фрагмент)

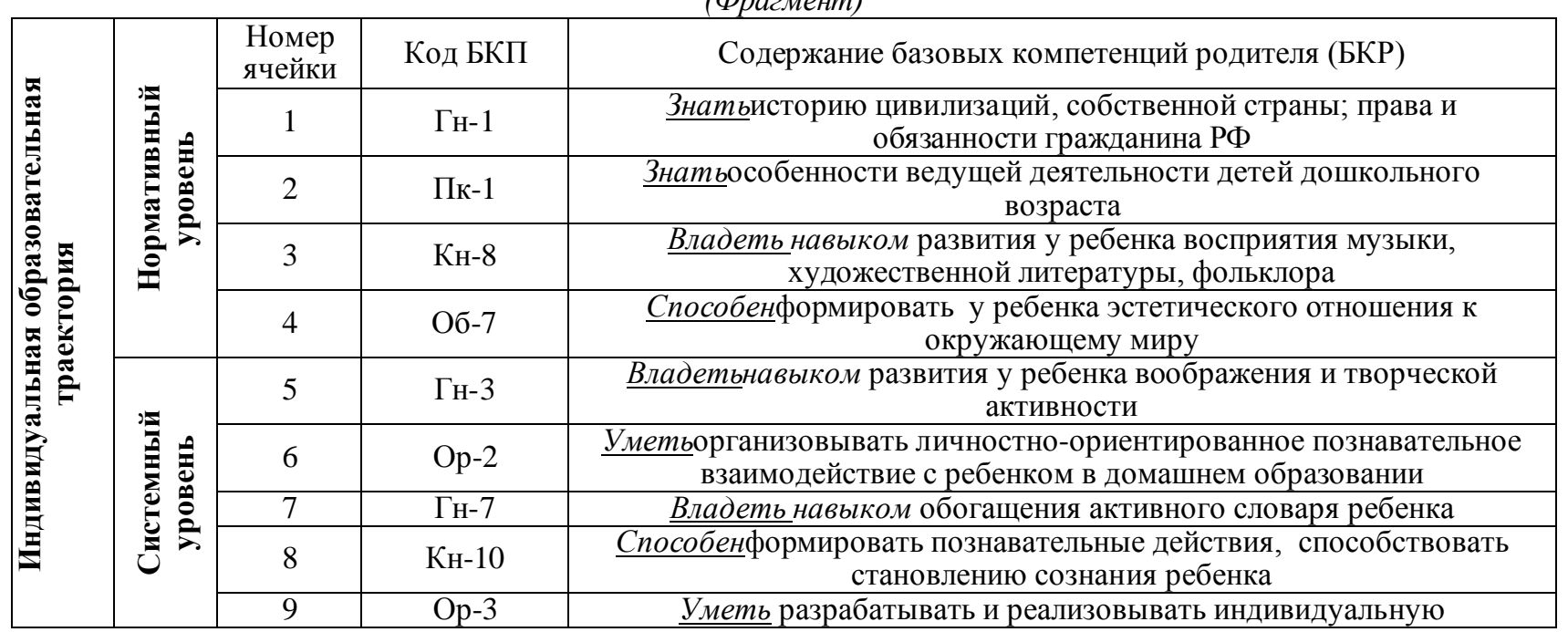




\begin{tabular}{|c|c|c|c|}
\hline & & & $\begin{array}{c}\text { образовательную траекторию с учетом личностных и возрастных } \\
\text { особенностей ребенка дошкольного возраста }\end{array}$ \\
\hline \multirow{3}{*}{ 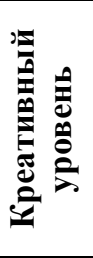 } & 10 & Об-7 & $\begin{array}{c}\text { Владетьнавыком воспитания самостоятельности, } \\
\text { целенаправленности и саморегуляции действий ребенка }\end{array}$ \\
\hline & 11 & Мт-8 & $\begin{array}{l}\text { Bладеть навыком становления личностно-значимых и социально- } \\
\text { одобряемых мотивов поведения ребенка дошкольного возраста }\end{array}$ \\
\hline & 12 & Op-5 & $\begin{array}{c}\text { Владеть навыком самосовершенствования, саморегулирования, } \\
\text { саморазвития (личностной рефлексией, смыслом жизни), развития } \\
\text { родительской деятельности }\end{array}$ \\
\hline \multirow{4}{*}{ 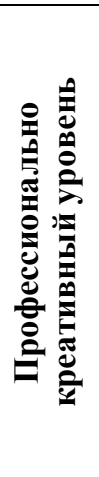 } & 13 & Мт-1 & $\begin{array}{l}\text { 3натьпути достижения образовательных результатов и способов } \\
\text { получения результатов обучения ребенка в домашнем образовании }\end{array}$ \\
\hline & 14 & Км-4 & $\begin{array}{c}\text { Bладеть навыком участия планирования и корректировке } \\
\text { образовательных задач (совместно с психологом и другими } \\
\text { специалистами) с учетом индивидуальных особенностей развития } \\
\text { ребенка на этапе детства }\end{array}$ \\
\hline & 15 & Op-11 & $\begin{array}{c}\text { Bладеть навыком участия в разработке основной } \\
\text { общеобразовательной программы образовательной организации в } \\
\text { соответствии с федеральным государственным образовательным } \\
\text { стандартом дошкольного образования } \\
\end{array}$ \\
\hline & 16 & Op-12 & $\begin{array}{c}\text { Владеть навыком участия в разработке и реализации программы } \\
\text { развития образовательной организации в целях создания безопасной } \\
\text { и комфортной образовательной среды }\end{array}$ \\
\hline
\end{tabular}

Таксономическая модель отражает принцип вложенности базовых компетенций, согласно которому единичные (далее не разложимые)компетенции могут входить в сложные, системные компетенции и становиться их компонентами.

Модель многофункциональна: цифры в еe ячейках могут указывать порядок нарастания сложности в постановке компетентностноориентированных образовательных целей или оценочных средств, используемых для определения уровня развития базовых компетенций и качества индивидуальной образовательной (в том числе и будущего[Исаева]).

В начале дистанционного обучения определяется цель вебинара и актуализируется потребность в уточнении структурызнанийродителей. Ее характеристика дана в таблице 4.

Таблица 4

Структура знаний родителей

\begin{tabular}{|c|c|c|}
\hline & & Родитель \\
\hline \multirow{4}{*}{ 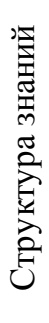 } & $\begin{array}{l}\text { Мировоззренческий } \\
\text { минимум (М) }\end{array}$ & $\begin{array}{c}\text { Минимальные знания, необходимые для реализации образовательной } \\
\text { деятельности в домашнем образовании ребенка }\end{array}$ \\
\hline & Базовые знания (Б) & $\begin{array}{c}\text { Знания, необходимые дляпроектирования и реализации образовательного } \\
\text { процесса в домашнем образовании ребенка }\end{array}$ \\
\hline & $\begin{array}{l}\text { Программные знания } \\
\text { (П) }\end{array}$ & $\begin{array}{l}\text { Знания, необходимые для образовательной деятельности по реализации } \\
\text { основной образовательной программы в домашнем образовании ребенка }\end{array}$ \\
\hline & $\begin{array}{l}\text { Сверхпрограммные } \\
\text { знания (C) }\end{array}$ & $\begin{array}{c}\text { Дополнительные по отношению к основной образовательной программе } \\
\text { знания, которые родитель приобретает самостоятельно }\end{array}$ \\
\hline
\end{tabular}

Следует также уточнить представление о теме дистанционного обучения, заданной проблеме, сформировать у родителей потребность в знании. 
Для адресной мотивацииродителей на достижение целив дистанционном обучении установленыуровни мотивации, построенные на основе иерархической теории потребностей А.Маслоу [5]. Они представлены в таблице 5.

Таблица 5

Связь иерархической теории потребностей А.Маслоу с уровнями мотивации родителей в образовательном прочессе

\begin{tabular}{|c|c|}
\hline \multirow{2}{*}{ Уровень мотивации } & Характеристика уровня мотивации \\
\hline & Родителя \\
\hline $\begin{array}{l}\text { 1. Уровень } \\
\text { экзистенциальных } \\
\text { потребностей }\end{array}$ & $\begin{array}{c}\text { Определяется потребностью в обеспечении защиты и безопасности своей } \\
\text { родительской деятельностив дошкольной организации: комфортная не- } \\
\text { принужденная обстановка; уютная атмосфера; возможности роста психолого- } \\
\text { педагогической культуры и поддержка уверенности в собственных педагогических } \\
\text { возможностях по развитию ребенка в домашнем образовании }\end{array}$ \\
\hline $\begin{array}{l}\text { 2. Уровень } \\
\text { коммуникативных } \\
\text { потребностей }\end{array}$ & $\begin{array}{c}\text { Характеризуется желанием стать частью родительского коллектива дошкольной } \\
\text { организации, необходимостью установленных доброжелательных образовательных } \\
\text { отношений с педагогами, другими родителями и специалистами при осуществлении } \\
\text { родительской деятельности по образованию, воспитанию и развитию ребенка }\end{array}$ \\
\hline $\begin{array}{c}\text { З.Уровень } \\
\text { потребностей } \\
\text { самоактуализации }\end{array}$ & $\begin{array}{c}\text { Характеризуется желанием субъекта реализоваться как родителю, } \\
\text { самосовершенствоваться в родительской деятельности, добиться уважения и } \\
\text { признания от семьи и других участников образовательного процесса }\end{array}$ \\
\hline $\begin{array}{l}\text { 4.Уровень } \\
\text { синтетических } \\
\text { потребностей }\end{array}$ & $\begin{array}{c}\text { Характеризуется интересом к вопросам развития и образования ребенка; желанием } \\
\text { проявлять свою индивидуальность; иметь свободу в выборе средств деятельности; } \\
\text { необходимостью сочетания различных возможностей для реализации творческих } \\
\text { способностей в домашнем образовании ребенка }\end{array}$ \\
\hline
\end{tabular}

Уровни мотивации задают границы блоков базовых компетенций родителей, как целей их дистанционного обучения.

Сформированные знания обеспечивают условия для их применения в соответствии со структуройумений, раскрытой в таблице 6.

Как следует из таблицы, родители понимают как работают знания на практике в условиях домашнего образования.

Как отмечает, М.И. Моисеева, «использование в рамках дистанционного обучения технологии обучения в сотрудничестве приводит к созданию особой образовательной среды, которая открыта для любой формы взаимного информационного обмена, построения отношений доверия и сотрудничества обмена идеями»[6].

Таблица 6

Структура умений родителей

\begin{tabular}{|c|c|c|}
\hline \multirow{3}{*}{ 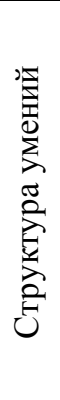 } & Фактическим (I) & $\begin{array}{l}\text { Предполагает умения выполнять образовательную деятельность по } \\
\text { реализации основной образовательной программы в домашнем } \\
\text { образовании ребенка }\end{array}$ \\
\hline & Алгоритмическим (II) & $\begin{array}{l}\text { Требует умения анализировать образовательную ситуацию, } \\
\text { адекватно ей применять типовые алгоритмы образовательной } \\
\text { деятельности в домашнем образовании ребенка с опорой на } \\
\text { родительский опыт и приобретенные навыки }\end{array}$ \\
\hline & Аналитическим (III) & $\begin{array}{lccrr}\text { Предусматривает } & \text { наличие } & \text { навыков } & \text { анализа, } & \text { оценки } \\
\text { образовательной } & \text { ситуации, создания собственного } & \text { алгоритма } \\
\text { образовательной } & \text { деятельности п по осуществлению } & \text { основной }\end{array}$ \\
\hline
\end{tabular}




\begin{tabular}{|l|l|l|}
\hline & образовательной программы в домашнем образовании ребенка \\
\cline { 2 - 3 } & Многофункциональным (IV) & Характеризуется способностью прогнозировать развитие ребенка в \\
образовательной деятельности, использовать созданные алгоритмы \\
действий в новых нестандартных условиях, активно привлекать \\
информационные технологии для проектирования, реализации и \\
усовершенствования основной образовательной программы и \\
формирования новых знаний и навыков
\end{tabular}

Обобщая вышеизложенное, можно сделать вывод, что элементы дистанционного курса дают родителям дошкольников возможность расширить сеть контактов с другими субъектами образовательного процесса (педагогами, специалистами) без необходимости приходить в детский сад, виртуальная аудитория «переносится на рабочее место или домой».

Преимущества для дошкольной организации заключаютсяв повышении квалификации педагогов и качества дошкольного образования за счет обучения родителей по вопросам развития и образования детей в условиях реализации ФГОС ДО.

\section{Литература:}

1. Веретенникова В.Б. Структурно-функциональная модель качества компетентностно-ориентированного образовательного процесса в системе дошкольного образования/Казанский педагогический журнал. 2015. № 5. Часть 2. - С. 76-81.

2. Веретенникова В.Б. Образовательная деятельность субъектов образовательного процесса в современной системе дошкольного образования / Качество Инновация Образование. - 2015. №9. - С. 8-16.

3. Веретенникова В.Б., Шихова О.Ф. Стратегические направления развития современной системы дошкольного образования// Современные проблемы науки и образования. - 2015. - № 6; URL: http:/www.scienceeducation.ru/130-23303 (дата обращения: 30.11.15)

4. Исаева Т.А., Шихова О.Ф. Тренинг как форма организации педагогической практики студентов/ Образование и наука.- 2014. № 9 (118).-C. 98-112. 
5. Психология труда: учебник для бакалавров / А.В. Карпов [и др.]; под ред.А.В.Карпова. -2-е изд. - М.: Издательство Юрайт, 2004. - 350с.

6. Ситуационный анализ или Анатомия кейс-метода / Ю. Сурмин [и др.]. Киев: Центр инноваций и развития, 2002. -286с.

7. Шихов Ю.А. Квалиметрический мониторинг качества фундаментальной подготовки в техническом вузе: моногр. М.; СПб.; Ижевск: Исследовательский центр проблем качества подготовки специалистов: Стикс: ИжГТУ, 2007. -208c.

8. Шихов Ю.А. Концептуальные основы мониторинга качества обучения в системе непрерывного образования / Казанский педагогический журнал.2008. № 1.-C. 3-6.

9. Шихов Ю.А. Некоторые проблемы организации мониторинга качества подготовки в системе «Школа - втуз» / Интеграция образования.- 2004. № 2.-C. 50-52. 